(c) 2012 Elsevier B.V. This manuscript version is made available under the CC-BY-NC-ND 4.0 license (http:// creativecommons.org/licenses/by-nc-nd/4.0/)

\title{
Dendrimers reduce toxicity of $A \beta$ 1-28 peptide during aggregation and accelerate fibril formation
}

Barbara Klajnert, Prof. ${ }^{* 1}$, Tomasz Wasiak, M.Sc. ${ }^{1}$, Maksim Ionov, Ph.D. ${ }^{1}$, Marcos FernandezVillamarin, M.Sc. ${ }^{2}$, Ana Sousa, M.Sc. ${ }^{2}$, Juan Correa, Ph.D. ${ }^{2}$, Ricardo Riguera, Prof. ${ }^{2}$, and Eduardo Fernandez-Megia, Prof. ${ }^{* 2}$

1Department of General Biophysics, University of Lodz, 141/143 Pomorska St., Lodz, Poland, e-mail: aklajn@biol.uni.lodz.pl, phone: +48 4263544 29, fax: +48 4263544 74;

2Department of Organic Chemistry and Center for Research in Biological Chemistry and Molecular Materials (CIQUS), University of Santiago de Compostela, Jenaro de la Fuente s/n, 15782 Santiago de Compostela, Spain, e-mail: ef.megia@usc.es, phone: +34 881815 727, fax: +34 881815704

${ }^{*}$ Corresponding authors

Short title: Dendrimers reduce toxicity of $A \beta$ 1-28 peptide.

Statement of funding: This work was funded by the project "Biological Properties and Biomedical Applications of Dendrimers" operated within Foundation for Polish Science TEAM programme, cofinanced by the European Regional Development Fund. Financial support is also acknowledged from the Spanish MICINN (CTQ2009-10963 and CTQ2009-14146-C0202) and the Junta de Galicia (10CSA209021PR). M. F-V. thanks the Spanish Ministry of Education for a FPU fellowship. The research was done within the frame of the COST Action TD0802 "Dendrimers for biomedical applications".

\begin{abstract}
The influence of a GATG (gallic acid-triethylene glycol) dendrimer decorated with 27 terminal morpholine groups ([G3]-Mor) on the aggregation process of Alzheimer's peptide has been investigated. Amyloid fibrils were formed from the $A \beta$ 1-28 peptide and the process was monitored by a ThT assay, changes in CD spectra, and transmission electron microscopy. In the presence of [G3]-Mor, more fibrils were built and the process significantly accelerated compared to a control. The cytotoxicity of (1) A $\beta$ and (2) the system [G3]-Mor/A $\beta$ was monitored at different stages of the aggregation process. Prefibrillar species were more toxic
\end{abstract}


than mature fibrils. [G3]-Mor significantly reduced the toxicity of $A \beta$, probably due to lowering the amount of prefibrillar forms in the system by speeding up the process of fibril formation.

Alzheimer's disease (AD) is the major cause of disability and death in the elderly. Amyloid deposits surrounding dying neurons, neurofibrillar degeneration with tangles, and cerebrovascular angiopathies are three main characteristics of $A D$ [1]. One of the main pathological hallmarks of $A D$ is the formation of amyloid plaques in the affected brain as a result of protein misfolding [2]. The major component of amyloid deposits is a 40-42 residue peptide called $\beta$-amyloid peptide $(A \beta)$, produced by endoproteolytic cleavage of an amyloid precursor protein (APP) [3]. The structure of $A \beta$ 1-40 has recently been published [4]. It adopts a compact, partially folded structure (with a central hydrophobic region forming a 310 helix from $\mathrm{H} 13$ to D23) predicted to be crucial in-pathway intermediates in fibrilogenesis that leads to creation of oligomers, protofibrils, and fibrils in equilibrium. Amyloid aggregates are formed when $A \beta$ is excessively produced, cleared too slowly, or in contact with proaggregating factors. Various aggregated forms of $A \beta$ act as potent and direct neurotoxic agents, eliciting a cascade of events leading to neuronal pathology and clinical manifestation of $A D$. Thus, clearance of $A \beta$ from the brain is first choice in therapies for $A D$ patients [5]. $A$ complementary and actively pursued therapeutic strategy for treating $A D$ is preventing aggregation of $A \beta$. For instance, efforts to synthesize small molecules that target $A \beta$ aggregates and at the same time complex metal-ions (that are known to facilitate $A \beta$ aggregation and produce reactive oxygen species associated to oxidative stress and neuropathology of $A D$ ) have been made $[6,7]$. Inorganic nanoparticles strongly inhibit $A \beta$ fibrillation by preferentially binding to oligomers [8]. Alternatively, dendrimers - globular, highly branched polymers - either inhibit or accelerate the production of fibrils $[9,10]$. A breakthrough in the use of dendrimers as therapeutic agents for AD has been the discovery that polyamidoamine (PAMAM) dendrimers can purge scrapie forms of prion protein ( $\mathrm{PrPsc}$ ) in vitro from infected brain extracts [11, 12]. Several mechanisms have been proposed to explain this dendrimer activity; interaction with peptide monomers, blocking of fibril ends, and disruption of existing fibrils [13].

One of the most important aspects of $A D$ is that neurotoxicity relates to $A \beta$ aggregates, not to newly solubilized peptides [14]. Mechanisms has been suggested to explain the cytotoxicity induced by $A \beta$ aggregates, such as activation of false signal transduction pathways that lead to apoptosis [15, 16], the generation of free radicals that result in oxidative stress and mitochondrial dysfunction [17], and the opening of ion-channels in membranes that leads to their depolarization [18]. 
Herein we report on the influence of GATG (gallic acid-triethylene glycol) dendrimers on the aggregation of an amyloid model peptide $A \beta$ 1-28, which contains the core region responsible for $A \beta$ aggregation. GATG has recently emerged as an interesting family of dendrimers that benefit from an easy structural modification, and an adequate aqueous solubility and biocompatibility due to their ethylene glycol side-chains [19-21]. The presence of peripheral azides in GATG dendrimers has been exploited for efficient functionalization by means of $\mathrm{Cu}(\mathrm{I})$-catalyzed azide-alkyne cycloaddition (CuAAC) [22, 23]. The resulting activated dendrimers have emerged as interesting agents in the study of the multivalent carbohydrate-receptor interaction [24], the dynamics of dendrimers [25], and the preparation of polyion complex micelles and dendriplexes for gene therapy [26 27]. GATG-based contrast agents for MRI have recently been reported [28]. Encouraged by the promising properties of GATG dendrimers as inhibitors of the dimerization of the capsid protein (CA) of HIV-1 [29], we have investigated their potential to influence the formation of amyloid fibrils and the toxicity of $A \beta$ 1-28. With this aim, a novel GATG dendrimer of generation 3, functionalized with 27 terminal morpholinoethyl groups ([G3]-Mor, Figure 1), has been prepared with CuAAC. $\mathrm{N}$-alkylated morpholines are characterized by physiological $\mathrm{pH} \mathrm{pKa}$ values, which makes them attractive ligands in dendrimer-amyloid peptide interactions. The formation of fibrils in the presence of [G3]-Mor has been confirmed using the thioflavin $T$ (ThT) assay, TEM observations and CD experiments. The cytotoxicity of $A \beta$ species was monitored by the MTT assay during the aggregation process in the absence and presence of the dendrimer. The cytotoxicity of [G3]-Mor was also assessed.

\section{Material and methods}

\subsection{Materials}

A synthetic peptide A 1 1-28 [DAEFRHDSGYEVHHQKLVFFAEDVGSNK] (purity >90\%) was purchased from JPT Peptide Technology GmbH (Germany). A peptide stock solution was kept in $10 \mathrm{mM}$ HEPES buffer at $\mathrm{pH}$ 7.4. Thioflavin $\mathrm{T}$ (ThT), heparin-sodium salt from porcine intestinal mucosa (H4784) and 3-(4,5-dimethylthiazol-2-yl)-2,5-diphenyltetrazolium bromide (MTT) were purchased from Sigma Chemical Company. All other chemicals were of analytical grade. Double-distilled water was used to prepare the other solutions. [G3]-Mor: [G3]- $\mathrm{N}_{3}$ (27 mg, $3.44 \mu \mathrm{mol}$, prepared according to Fernandez-Megia et al. [20]) was dissolved in $t$ - $\mathrm{BuOH}(0.46 \mathrm{ml})$ and $\mathrm{H}_{2} \mathrm{O}(0.30 \mathrm{ml})$. 4-(3-butyn-1-yl)morpholine (26 mg, 0.186 mmol, prepared according to Smaill el at. [30]) and freshly prepared aqueous solutions of $\mathrm{CuSO}_{4}(46 \mu \mathrm{L}, 4.64 \mu \mathrm{mol})$ and sodium ascorbate $(116 \mu \mathrm{L}, 23.2 \mu \mathrm{mol})$, were added. The solution was stirred at room temperature for $72 \mathrm{~h}$. $\mathrm{Aq} \mathrm{HCl}(0.1 \mathrm{ml}, 0.1 \mathrm{M})$ was added and the mixture purified by ultrafiltration (Amicon YM1, $5 \times 30 \mathrm{ml} \mathrm{H}_{2} \mathrm{O}$ ) before being freeze-dried to 
yield the hydrochloride salt of [G3]-Mor (38.8 mg, 90\%) as a pale yellow foam. ${ }^{1} \mathrm{H}-\mathrm{NMR}$ (500 $\left.\mathrm{MHz}, \mathrm{D}_{2} \mathrm{O}\right)$ ס: 7.90 (br s, 27H), 7.23-6.99 (m, 26H), 4.56 (br s, 54H), 4.21-3.48 (m, 498H), 3.26 (br s, 2H), 3.19-2.71 (m, 216H), 1.56 (br s, 2H), 0.90 (br s, 3H). ${ }^{13} \mathrm{C} \mathrm{NMR} \mathrm{(100} \mathrm{MHz,}$ $\left.\mathrm{D}_{2} \mathrm{O}\right)$ $\delta: 169.6,169.5,152.9,152.7,144.6,140.7,130.3,125.0,107.2,73.2,71.0,70.9,70.7$, $70.4,70.0,69.7,69.4,65.6,57.4,52.9,50.9,40.7,21.4,11.8$. IR $\left(\mathrm{KBr}, \mathrm{cm}^{-1}\right) 3288,2928$, $2870,1651,1118$. [G3]-Mor was dissolved in $10 \mathrm{mM}$ HEPES buffer at $\mathrm{pH} 7.4$.

\subsection{Formation of amyloid fibrils - ThT assay}

Aggregation was monitored using the dye, ThT, whose fluorescence depends on the aggregate formation. A stock solution of $A \beta$ 1-28 peptide $(1 \mathrm{mM})$ in HEPES, pH 7.4 (kept at 4 ${ }^{\circ} \mathrm{C}$ and used within few days) was diluted to $50 \mu \mathrm{M}$. ThT was then added and its concentration in the sample set to match $35 \mu \mathrm{M}$ and a pH of 5.5 with aliquots of aq $\mathrm{HCl}$. Aggregation was triggered by the addition of $0.041 \mathrm{mg} / \mathrm{ml}$ heparin. Fluorescence was measured with a Perkin-Elmer LS-50B spectrofluorimeter. Experiments were performed at $37^{\circ} \mathrm{C}$ with continuous stirring of the sample. The kinetics of aggregation was monitored by the changes in fluorescence intensity during the course of the experiment, with excitation and emission wavelengths of 450 and $490 \mathrm{~nm}$, respectively. The excitation and emission slit widths were set at $5 \mathrm{~nm}$.

\subsection{Formation of amyloid fibrils - transmission electron microscopy observations}

Fifteen $\mu \mathrm{l}$ of a sample were removed from a fluorimetric cuvette after completion of aggregation ( Section 2.2) and placed on a copper grid with carbon surface for $10 \mathrm{~min}$ and dried with a filter paper. The sample was stained with $2 \%(\mathrm{~m} / \mathrm{v})$ uranyl acetate for $2 \mathrm{~min}$ and dried. Transmission electron microscopy images were taken with a Hitachi H-7000 (75 kV) microscope.

\subsection{Formation of amyloid fibrils - Circular dichroism experiments}

CD in the far UV region measurements made with a J-815 CD spectrometer (Jasco). A 1 1-28 samples was prepared analogously as for a ThT assay except by adding ThT. CD spectra were recorded between 260 and $190 \mathrm{~nm}$ using $0.05 \mathrm{~cm}$ path-length quartz sandwich cell (Helma). The recording parameters were bandwidth - $1.0 \mathrm{~nm}$, slit width - auto, response - 1 $\mathrm{s}$, scan speed $-50 \mathrm{~nm} / \mathrm{min}$, and step resolution $-0.2 \mathrm{~nm}$. The number of scans varied between 3 and 5 for each sample. Measurements were made at different time intervals during aggregation $(0,5,60$, and $120 \mathrm{~min}$ from the beginning of the process). CD spectra were corrected by subtracting CD spectra obtained for [G3]-Mor dissolved in a buffer without the peptide. The mean residue ellipticity, $\theta$, expressed as a value deg $\mathrm{cm}^{2} \mathrm{dmol}^{-1}$, was calculated.

\subsection{Cell culture}


Immortalized Chinese hamster fibroblast (B14, ATCC no. CCL-14) were used to measure the cytotoxicity of [G3]-Mor, as also the monomeric and aggregated forms of $A \beta$ 1-28. Cells were grown in Dulbecco's Modified Eagle's Medium Gluta-MAX (DMEM) (Gibco, UK) supplemented with $10 \%$ inactivated fetal bovine serum (Sigma Chemical Company) at $37^{\circ} \mathrm{C}$ in a humidified incubator with $5 \% \mathrm{CO}_{2}$ in air. Medium was replaced every 3 to 4 days and cells were split for subcultures $1: 10$ every 4 to 5 days.

\subsection{Cytotoxicity of [G3]-Mor - MTT assay}

Five $\times 10^{3}$ cells were seeded per well in 96 -well plates with growth media $(100 \mu \mathrm{l})$. Cells were washed with phosphate-buffer saline (PBS: $2 \mathrm{mM} \mathrm{KH}_{2} \mathrm{PO}_{4}, 10 \mathrm{mM} \mathrm{Na}_{2} \mathrm{HPO}_{4}, 150 \mathrm{mM} \mathrm{NaCl}$, $2.7 \mathrm{mM} \mathrm{KCl}, 1 \mathrm{mM} \mathrm{CaCl}, 0.5 \mathrm{mM} \mathrm{MgCl}_{2}, \mathrm{pH}$ 7.4). Fresh medium and [G3]-Mor (0.05-1.5 $\mu \mathrm{M})$ were added $24 \mathrm{~h}$ after seeding. After $2 \mathrm{~h}$, the medium with [G3]-Mor was removed, cells were washed twice with PBS, and fresh medium added. After $72 \mathrm{~h}, 50 \mu \mathrm{l}$ MTT $(0.5 \mathrm{mg} / \mathrm{ml}$ in PBS) was added to each well for $4 \mathrm{~h}$, and the supernatant (containing unreacted dye) was replaced with dimethyl sulfoxide (DMSO) $(100 \mu \mathrm{l} /$ well). Plates were shaken and absorbance measured at $540 \mathrm{~nm}$ with a reference at $720 \mathrm{~nm}$ at a Cary 50 BIO UV-Visible Spectrophotometer. Yellow MTT formed purple formazan by mitochondrial dehydrogenases in the living cells, while no activity of mitochondrial dehydrogenases is detected in dead and damage cells [31]. Cell viability was calculated according to equation:

$$
\text { cell viability }[\%]=\left(x / x_{C}\right) \times 100
$$

where $x$ is the absorbance of cells treated with [G3]-Mor and $x_{C}$ the absorbance of untreated (control) cells. An $\mathrm{IC}_{50}$ value of cell viability was obtained graphically.

\subsection{Cytotoxicity of $A \beta 1-28$ forms}

Two and a half $\times 10^{3}$ cells were seeded per well in a 96-well plate with growth media $(50 \mu \mathrm{l})$. $A \beta$ 1-28 peptide samples (collected during the aggregation process) were added to cells at $10 \mu \mathrm{M}$. A $\beta$ was removed after $2 \mathrm{~h}$ later, the cells washed twice with PBS, and fresh medium added. The MTT assay was used as before (section 3.4). The same procedure was applied when $A \beta$ 1-28 aggregated in the presence of [G3]-Mor.

\subsection{Statistics}

Data were expressed as means $\pm S D$, and their statistical significance was analyzed by Tucey's $t$-test using StatSoft, Inc. (2000) STATISTICA software for Windows.

\section{Results}

Amyloid fibrils of $A \beta$ 1-28 were formed in vitro and the aggregation process was monitored over time by fluorescence in the ThT assay (Figure 2), having previously checked that ThT did not bind to [G3]-Mor. ThT is a dye with a fluorescence intensity that depends strictly on the presence of fibrils in the system - the more fibrils formed, the higher the ThT fluorescence intensity. A curve characteristic for a nucleation-dependent process was taken as a control 
(the system without dendrimer). The lowest concentration of [G3]-Mor added (0.01 $\mu \mathrm{M})$ had almost no effect on aggregation, whereas a $10 \mathrm{x}$ higher concentration caused a slight increase in fibril production. The most pronounced effect was obtained with a $1 \mu \mathrm{M}$ dimer, which led to the production of far more fibrils and a significant acceleration of aggregation. $A$ plateau was reached after $120 \mathrm{~min}$, compared with $\sim 210 \mathrm{~min}$.

The effect of [G3]-Mor on the morphology of $A \beta$ 1-28 amyloid aggregates was followed by TEM. For control samples (Figure 3A) and samples containing $1 \mu \mathrm{M}$ of [G3]-Mor (Figure 3B), characteristic long fibrils were seen. However, the amount of fibrils formed in $1 \mu \mathrm{M}$ [G3]-Mor during aggregation was significantly higher.

The amount of fibrils produced, as judged by TEM and changes in ThT fluorescence intensity were compared with alterations in CD spectra. CD experiments were carried out for the control (without [G3]-Mor) and for the system when [G3]-Mor was present at $1 \mu \mathrm{M}$. CD spectra were recorded in the region of 190-260 nm (Figure 4A). The CD signal here reflects the basic secondary structural features of peptides. The spectrum obtained for nonaggregated $A \beta$ 1-28 had a broad minimum between 195 and $210 \mathrm{~nm}$ that decreased as the aggregation developed. After addition of [G3]-Mor to $A \beta$ 1-28, the process was faster, as illustrated by the changes in residue mean ellipticity for $\lambda=201 \mathrm{~nm}$ during aggregation (Figure 4B).

Different states of $A \beta$ peptides that are formed during the aggregation process are believed to be associated with neurotoxicity in AD. The effect of [G3]-Mor on the toxicity of AB 1-28 was studied during the progress of amyloid fibril formation by the MTT test (Figure 5). The cytotoxicity of samples taken every $30 \mathrm{~min}$ was determined for a control and for the experiments with [G3]-Mor at 0.2 and $0.02 \mu \mathrm{M}$ (molar ratios $A \beta /[G 3]-M o r ~ e q u a l e d$ to 50 and 500 that correspond to [G3]-Mor concentrations of 1 and $0.1 \mu \mathrm{M}$ in the ThT assay). Before the aggregation process started, the $A \beta$ was almost non-toxic. Toxicity increased significantly after $30 \mathrm{~min}$ and reached a maximum after $90 \mathrm{~min}$ in the control. Toxicity decreased and after $180 \mathrm{~min}$, cell viability reached the same level as at $30 \mathrm{~min}$. For samples in which [G3]Mor was present, no toxicity was seen during the first $30 \mathrm{~min}$ of aggregation. Nevertheless, [G3]-Mor significantly reduced the cytotoxicity of samples taken at 60, 90, and 120 min (times for which the highest toxic effect was observed in control samples) in a concentrationdependent fashion.

The cytotoxicity of [G3]-Mor was also checked to confirm it was innocuous at 0.02 and 0.2 $\mu \mathrm{M}$. Indeed, cell viability started decreasing when the concentration of [G3]-Mor reached 0.5 $\mu \mathrm{M}$ (Figure 6). 


\section{Discussion}

Dendrimers have been intensively explored as anti-amyloid agents in the last few years [13, 32, 33]. The formation of insoluble, fibrillar protein aggregates is a common of many neurodegenerative disorders, such as AD, Parkinson's disease and prion disorders. Dendrimers have a high affinity for proteins [34, 35], which has been used to explain their interference with amyloidogenesis through several mechanisms (see Introduction). Interestingly, most of the previously tested dendrimers block fibril formation at high concentrations, whereas they accelerate fibril production at lower concentrations $[9,13,36]$. This is typically the pattern for fibril disrupting agents. Inhibitors administered in low doses cause a moderate level of fibril breakage in amyloidogenic processes, and may be responsible for speeding up the formation of aggregates by creating new free-ends that serve as sites of replication. Conversely, the very same inhibitors can be effective at higher doses when breakage is very fast.

With [G3]-Mor, it was soon revealed that it affected the process of amyloidogenesis in a strikingly different way to that of most other dendrimers. Indeed, when [G3]-Mor was used at high concentrations, fibril formation was not inhibited, but aggregation was faster and increased amounts of fibrils were formed, a seemingly undesirable effect. Thus, although for many years the central role of aggregated forms of $A \beta$ in $A D$ pathogenesis has stimulated the development of therapeutic approaches designed to prevent fibril formation (fibrillar forms of $A \beta$ being necessary for neurotoxicity) [37], recent studies show that alternative $A \beta$ assemblies, including small oligomers and fibril intermediates, can also be neurotoxic [38]. For instance, correlation of neurological symptoms of AD with insoluble amyloid load seems to be much worse than with oligomers [39], which have been found in brains of AD patients [40]. In another study, young APP transgenic mice underwent synaptic electrophysiological and behavioral changes before amyloid plaques were formed [41,42]. It is also known that soluble oligomeric $A \beta$ blocks synaptic plasticity is required for memory formation, particularly in the hippocampus where neuronal loss occurs as the disease progresses [43]. In addition, others have shown that pre-fibrillar assemblies interact with synthetic phospholipid bilayers and cell membranes, possibly destabilizing them and impairing specific membrane-bound proteins $[44,45]$. Disclosure of oligomer toxicity has an immediate practical aspect: therapeutic strategies aimed at the destabilization of $A \beta$ fibrils might prove counterproductive and lead to an increase in the level of oligomers. It seems more important to check the toxicity of these systems and how this changes during aggregation than trying to stop fibril formation.

In our studies, cytotoxicity of was checked by the MTT assay. A small quantity of a sample was taken every 30 minutes from a cuvette where the aggregation progressed (control). Before the aggregation started, no toxic effect was found (time zero). Regarding the 
cytotoxicity of non-aggregated and aggregated forms of $A \beta 1-28$, this is consistent with the monomeric $\alpha$-helical conformation being neurotrophic and becoming neurotoxic only after transformation to an oligomeric $\beta$-sheet conformation [46]. The toxic effect progressed for up to $90 \mathrm{~min}$, with minimal cell viability. Then toxicity decreased, and after $180 \mathrm{~min}$ reached a similar level to in the initial $30 \mathrm{~min}$. Mature amyloid fibrils were substantially less harmful to cells than their precursors. When similar experiments involved $A \beta /[G 3]-$ Mor mixtures prepared at a molar ratio equal to 50 , toxicity was substantially decreased. This effect was even more pronounced when [G3]-Mor was 10x higher.

The most likely role played by [G3]-Mor in the reduction of toxicity relates to the faster and higher production of fibrils, with concomitant reduction of the concentration of prefibrillar forms, which in the control experiment are seen as ultimately responsible for its toxicity. Moreover, good correlation is observed between the times for minimal cell viability and $\sim 50 \%$ of maximal fluorescence intensity in the ThT assay (90 min for the control and $30 \mathrm{~min}$ for the $A \beta /[G 3]-M o r$ system at ratio of 50). It means that agents that accelerate the fibril formation might have a beneficiary effect in terms of reducing $A \beta$ toxicity. This represents an alternative approach to the search for inhibitors of the formation of both fibrillar and oligomeric morphologies, such as trehalose. Trehalose inhibits formation of fibrils and oligomers for $A \beta$ 1-40 that results in reduced toxicity against SH-SY5Y cells. However, when trehalose was co-incubated with $A \beta$ 1-42, it only inhibited formation of the fibrillar morphology, and no protective effect on SH-SY5Y cells was seen [47]. The behavior of the tested dendrimer proves that toxicity can be reduced not only by stopping aggregation, but also by accelerating the formation of mature fibrils that are much less harmful to cells than prefibrillar forms.

To conclude, a GATG dendrimer decorated with 27 terminal morpholine groups ([G3]-Mor) accelerates at non-toxic concentrations $A \beta$ fibril formation at $A \beta /$ dendrimer ratios 50 and 500 . Even though the final concentration of fibrils was higher in the presence of [G3]-Mor, the $A \beta$ toxicity was significantly lower. This encourages the monitoring of whether the same phenomenon is observed ith $A \beta 1-40$ and $A \beta$ 1-42. If this is the case, it may have a practical significance in nanomedicine.

\section{Acknowledgements}

We thank Dr. Josep Cladera for a fruitful discussion and valuable comments.

\section{References}

1. Drouet B, Pinçon-Raymond M, Chambaz J, Pillot T. Molecular basis of Alzheimer's disease. Cell Mol Life Sci 2000;57:705-15. 
2. DeToma AS, Salamekh S, Ramamoorthy A, Lim MH. Misfolded proteins in Alzheimer's disease and type II diabetes. Chem Soc Rev 2012;41:608-21.

3. Selkoe DJ. Physiological production of the $\beta$-amyloid protein and the mechanism of Alzheimer's disease. Trends Neurosci 1993;16:403-9.

4. Vivekanandan S, Brender JR, Lee SY, Ramamoorthy A. A partially folded structure of amyloid-beta (1-40) in an aqueous environment. Biochem Biophys Res Commun 2011;411:312-6.

5. Hardy J, Selkoe DJ. The amyloid hypothesis of Alzheimer's disease: progress and problems on the road to therapeutics. Science 2002;297: 353-6.

6. Choi JS, Braymer JJ, Nanga RPR, Ramamoorthy A, Lim MH. Design of small molecules that target metal-A $\beta$ species and regulate metal-induced $A \beta$ aggregation and neurotoxicity. Proc Natl Acad Sci U S A 2010;107: 21990-5.

7. Hindo SS, Mancino AM, Braymer JJ, Liu Y, Vivekanandan S, Ramamoorthy A, et al. Small molecule modulators of copper-induced $A \beta$ aggregation. J Am Chem Soc 2009;131:16663-5.

8. Yoo SI, Yang M, Brender JR, Subramanian V, Sun K, Joo NE, et al. Inhibition of amyloid peptide fibrillation by inorganic nanoparticles: functional similarities with proteins. Angew Chem Int Ed 2011;50:5110-5.

9. Klajnert B, Cortijo-Arellano M, Bryszewska M, Cladera J. Influence of heparin and dendrimers on the aggregation of two amyloid peptides related to Alzheimer's and prion diseases. Biochem Biophys Res Commun 2006;339:577-82.

10. Klajnert B, Cladera J, Bryszewska M. Molecular interactions of dendrimers with amyloid peptides: pH dependence. Biomacromolec2006;7:2186-91.

11. Supattapone S, Nguyen HO-B, Cohen F, Prusiner SB, Scott MR. Elimination of prions by branched polyamines and implications for therapeutics. Proc Natl Acad Sci U S A 1999;96:14529-34.

12. Supattapone S, Wille H, Uyechi L, Safar J, Tremblay P, Szoka FC, et al. Branched polyamines cure prion-infected neuroblastoma cells. J Virol2001;75:3453-61.

13. Klajnert B, Cortijo-Arellano M, Cladera J, Bryszewska M. Influence of dendrimer's structure on its activity against amyloid fibril formation. Biochem Biophys Res Commun 2006;345:21-8.

14. Pike CJ, Burdick D, Walencewicz AJ, Glabe CG, Cotman CW. Neurodegeneration induced by $\beta$-amyloid peptides in vitro: the role of peptide assembly state. J Neurosci 1993;13:1676-87. 
15. El Khoury J, Hickman SE, Thomas CA, Cao L, Silverstein SC, Loike JD. Scavenger receptor-mediated adhesion of microglia to $\beta$-amyloid fibrils. Nature 1996;382:716-9.

16. Paresce DM, Ghosh RN, Maxfield FR. Microglia cells internalize aggregates of the Alzheimer's disease amyloid $\beta$-protein via a scavenger receptor. Neuron 1996;17:553-65.

17. Behl C, Davis JB, Lesley R, Schubert D. Hydrogen peroxide mediates amyloid- $\beta$ toxicity. Cell 1994;77:817-27.

18. Arispe N, Rojas E, Pollard HB. Alzheimer disease amyloid- $\beta$ protein forms calcium channels in bilayer membranes: blockade by tromethamine and aluminium. Proc Natl Acad Sci U S A 1993;90:561-71.

19. Fernandez-Megia E, Correa J, Rodríguez-Meizoso I, Riguera R. A click approach to unprotected glycodendrimers. Macromolecules 2006;39: 2113-20.

20. Fernandez-Megia E, Correa J, Riguera R. qClickableq PEG-dendritic block copolymers. Biomacromolecules 2006;7:3104-11.

21. Meunier SJ, Wu Q, Wang SN, Roy R. Synthesis of hyperbranched glycodendrimers incorporating a-thiosialosides based on a gallic acid core. Can J Chem 1997;75:1472-82.

22. Rostovtsev VV, Green LG, Fokin VV, Sharpless KB. A stepwise huisgen cycloaddition process: copper(i)-catalyzed regioselective qligationq of azides and terminal alkynes. Angew Chem Int Ed 2002; 41:2596-9.

23. Tornoe CW, Christensen C, Meldal M. Peptidotriazoles on solid phase: $[1,2,3]$-triazoles by regiospecific copper(i)-catalyzed 1,3-dipolar cycloadditions of terminal alkynes to azides. $J$ Org Chem 2002;67:3057-64.

24. Munoz EM, Correa J, Fernandez-Megia E, Riguera R. Probing the relevance of lectin clustering for the reliable evaluation of multivalent carbohydrate recognition. J Am Chem Soc 2009;131:17765-7.

25. Novoa-Carballal R, Sawen E, Fernandez-Megia E, Correa J, Riguera R, Widmalm G. The dynamics of GATG glycodendrimers by NMR diffusion and quantitative $13 \mathrm{C}$ relaxation. Phys Chem Chem Phys 2010; 12:6587-9.

26. Sousa-Herves A, Fernandez-Megia E, Riguera R. Synthesis and supramolecular assembly of clicked anionic dendritic polymers into polyion complex micelles. Chem Commun 2008;27:3136-8.

27. Ravina M, de la Fuente M, Correa J, Sousa-Herves A, Pinto J, Fernandez-Megia E, et al. Core-shell dendriplexes with sterically induced stoichiometry for gene delivery. Macromolecules 2010;43:6953-61. 
28. Fernandez-Trillo F, Pacheco-Torres J, Correa J, Ballesteros P, Lopez-Larrubia P, Cerdán $S$, et al. Dendritic MRI contrast agents: an efficient prelabeling approach based on CuAAC. Biomacromolecules 2011;12: 2902-7.

29. Domenech R, Abian O, Bocanegra R, Correa J, Sousa-Herves A, Riguera R, et al. Dendrimers as potential inhibitors of the dimerization of the capsid protein of HIV-1. Biomacromolecules 2010;11:2069-78.

30. Smaill JB, Rewcastle GW, Loo JA, Greis KD, Chan OH, Reyner EL, et al. Tyrosine kinase inhibitors. 17. Irreversible inhibitors of the epidermal growth factor receptor: 4(phenylamino)quinazoline- and 4-(phenylamino)pyrido[3,2-d]pyrimidine-6-acrylamides bearing additional solubilizing functions. J Med Chem 2000;43:1380-97.

31. Hansen MB, Nilsen SE, Berg K. Re-examination and further development of a précis and rapid dye for measuring cell growth/cell kill. J Immunol Methods 1989;29:203-10.

32. Cordes H, Boas U, Olsen P, Heegaard PMH. Guanidino- and ureamodified dendrimers as potent solubilizers of misfolded prion protein aggregates under non-cytotoxic conditions: dependence on dendrimer generation and surface charge. Biomacromolecules 2007;8:357883.

33. Rekas A, Lo V, Gadd GE, Cappai R, You SI. PAMAM dendrimers as potential agents against fibrillation of $\alpha$-synuclein, a Parkinson's disease-related protein. Macromolec Biosci 2009;9:230-8.

34. Klajnert B, Stanislawska L, Bryszewska M, Palecz B. Interactions between PAMAM dendrimers and bovine serum albumin. Biochim Biophys Acta 2003;1648:115-26.

35. Shcharbin D, Klajnert B, Bryszewska M. The effect of PAMAM dendrimers on human and bovine serum albumins at different $\mathrm{pH}$ and $\mathrm{NaCl}$ concentrations. J Biomater Sci Polymer Edn 2005;16:1081-93.

36. Klajnert B, Appelhans D, Komber H, Morgner N, Schwarz S, Richter S, et al. The influence of densely organized maltose shells on the biological properties of poly(propylene imine) dendrimers: new effects depending on H-bonding-a comparison study with unmodified and cationic counterparts. Chem Eur J 2008;14:7030-41.

37. Soto C. Alzheimer's and prion diseases as disorders of protein conformation: implication for the design of novel therapeutic approaches. J Mol Med 1999;77:412-8.

38. Walsh DM, Klyubin I, Foldeeva JV, Rowan MJ, Selkoe DJ. Amyloidbeta oligomers: their production, toxicity and therapeutic inhibition. Biochem Soc Trans 2002;30:534-83. 
39. Klein WL, Krafft GA, Finch CE. Targeting small Abeta oligomers: the solution to an Alzheimer's disease conundrum? Trends Neurosci 2001; 24:219-24.

40. Kayed R, Head E, Thompson JL, Mclntire TM, Milton SC, Cotman CW, et al. Common structure of soluble amyloid oligomers implies common mechanism of pathogenesis. Science 2003;300:486-9.

41. Hsia AY, Masliah E, McConlogue L, Yu GQ, Tatsuno G, Hu K, et al. Plaque-independent disruption of neuronal circuits in Alzheimer's disease mouse models. Proc Natl Acad Sci U S A 1999;96:3228-33.

42. Mucke L, Masliah E, Yu GQ, Mallory M, Rockenstein EM, Tatsuno G, et al. High-level neuronal expression of $A \beta$ 1-42 in wide-type human amyloid protein precursor transgenic mice: synaptotoxicity without plaque formation. J Neurosci 2000;20:4050-8.

43. Walsh DM, Selkoe DJ. A $\beta$ oligomers-a decade of discovery. J Neurochem 2007;101:1172-84.

44. Zhu YJ, Lin $H$, Lal R. Fresh and nonfibrillar amyloid $\beta$ protein (1-40) induces rapid cellular degeneration in aged human fibroblasts: evidence for A $\mathrm{PP}$-channel-mediated cellular toxicity. FASEB J 2000; 14:1244-54.

45. Kourie JI, Shorthouse AA. Properties of cytotoxic peptide-induced ion channels. Am J Physiol Cell Physiol 2000;278:C1063-87.

46. Talafous J, Marcinkowski KJ, Klopman G, Zamorski MG. Solution structure of residues 128 of the amyloid $\beta$-peptide. Biochemistry 1994; 33:7788-96.

47. Liu R, Barkhordarian H, Emadi S, Park CB, Sierks MR. Trehalose differentially inhibits aggregation and neurotoxicity of beta-amyloid 40 and 42 . Neurobiol Dis 2005;20:74-81. 
Figure legends:

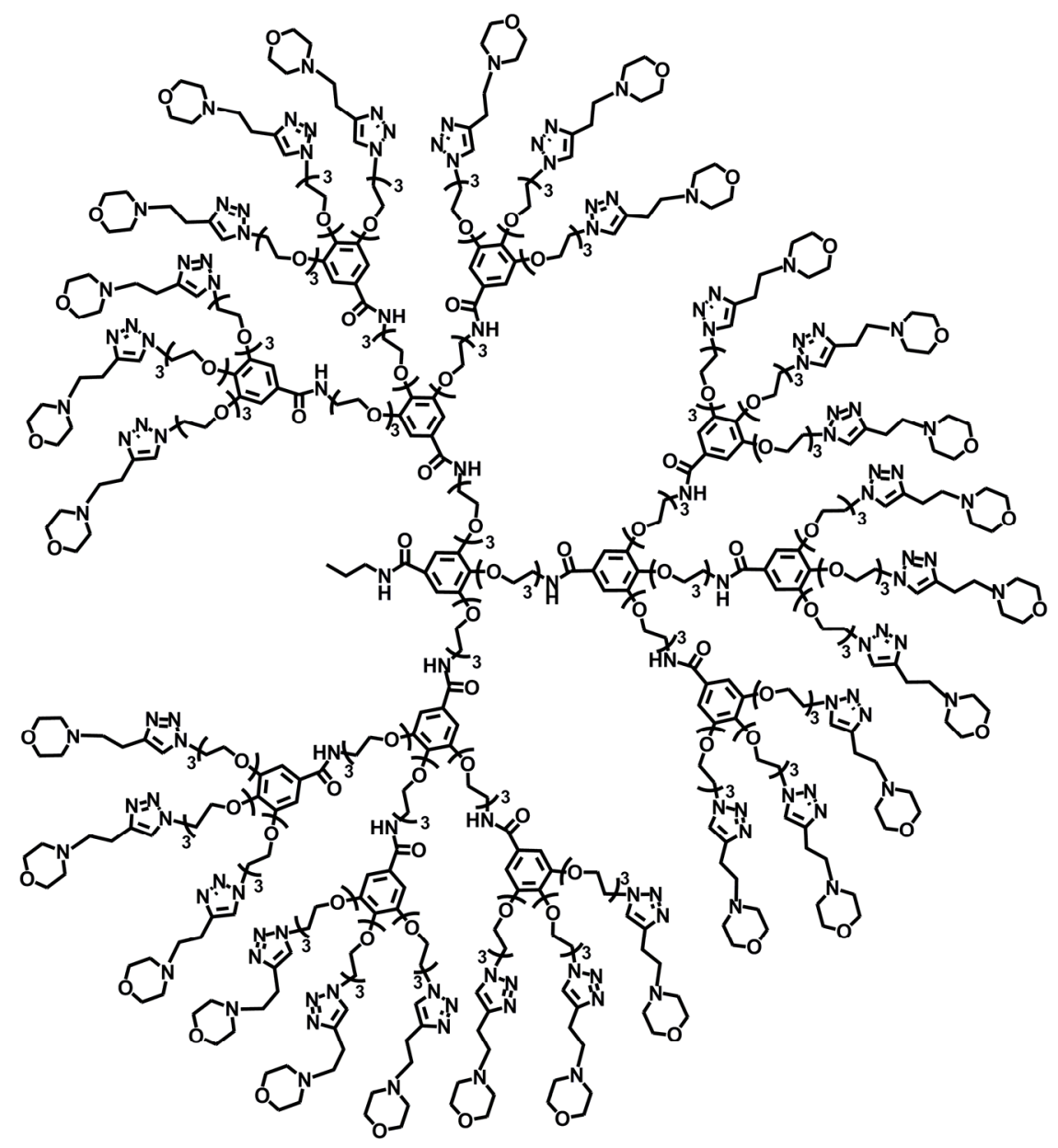

Figure 1. Structure of [G3]-Mor.

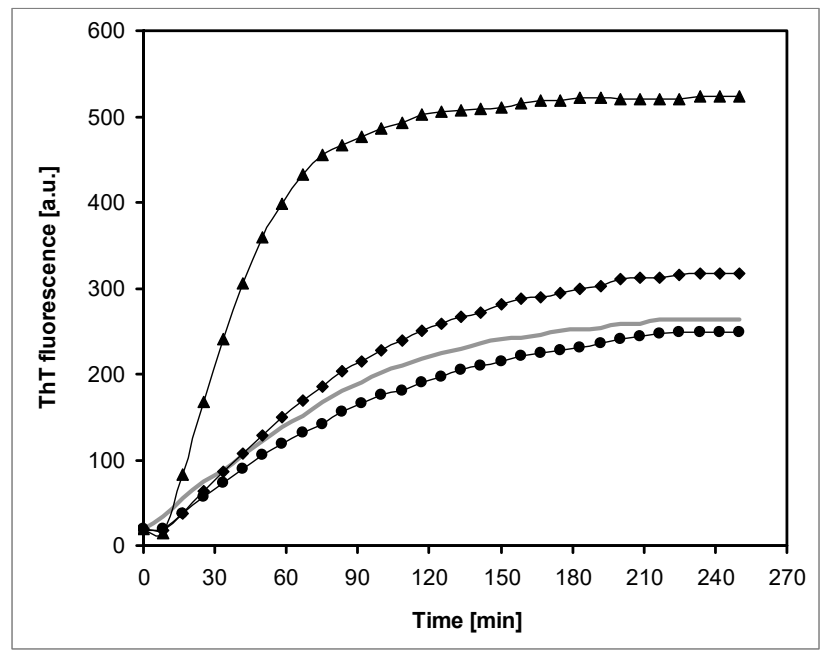

Figure 2. Variation of the fluorescence of ThT during the aggregation of $A \beta \quad 1-28$ in the absence (grey line) and presence of [G3]-Mor at $0.01 \mu \mathrm{M}$ (circles), $0.1 \mu \mathrm{M}$ (rombs), $1 \mu \mathrm{M}$ (triangles). 

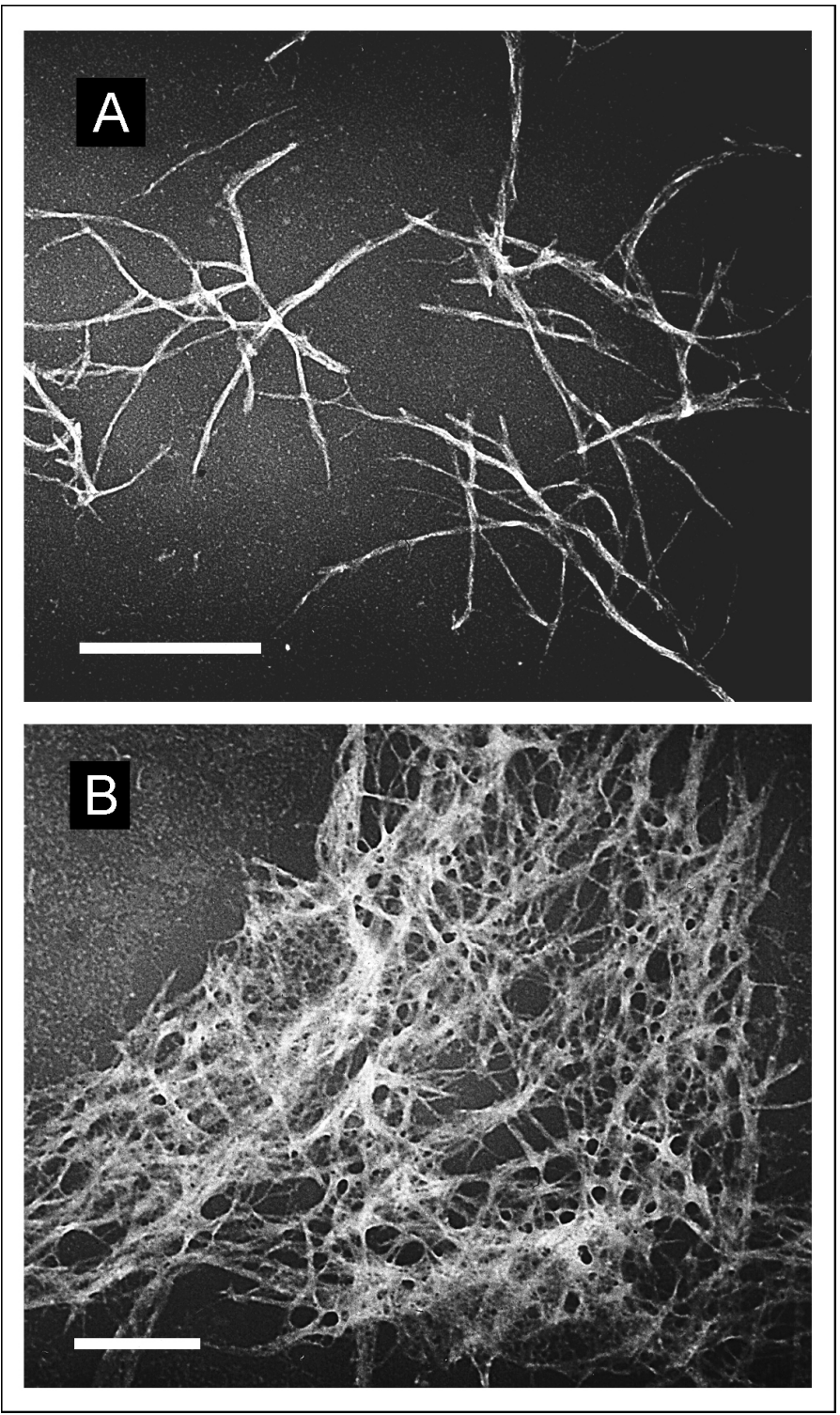

Figure 3. Electron micrographs of $A \beta$ 1-28 samples at the end of aggregation without [G3]Mor $(A)$, and in the presence of $1 \mu \mathrm{M}$ [G3]-Mor (B). The length of the bar is $200 \mathrm{~nm}$. 

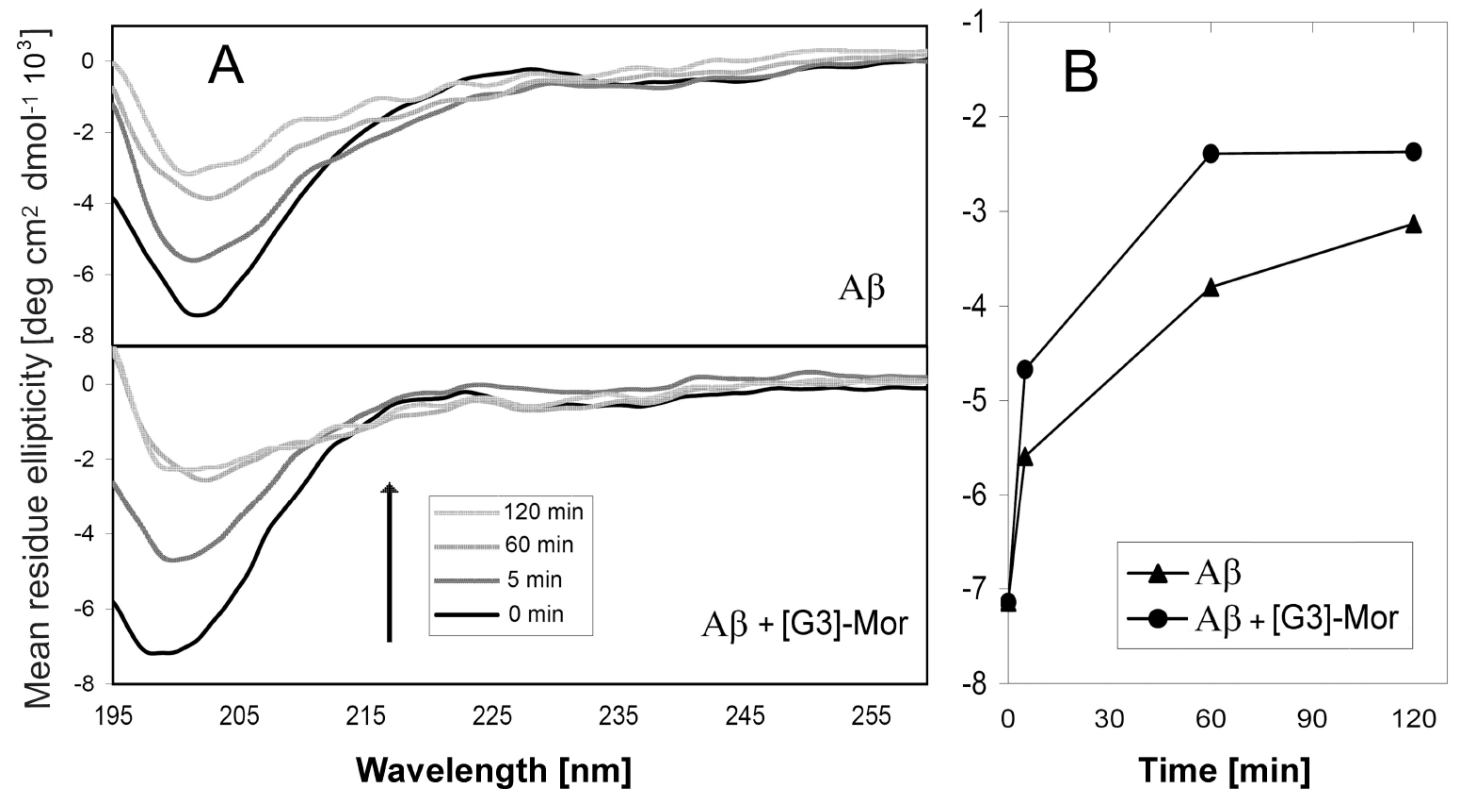

Figure 4. CD spectra of $A \beta$ 1-28 during aggregation (A) in the absence of [G3]-Mor - top panel, and in the presence of $1 \mu \mathrm{M}$ [G3]-Mor - bottom panel. Changes in mean residue ellipticity (B).

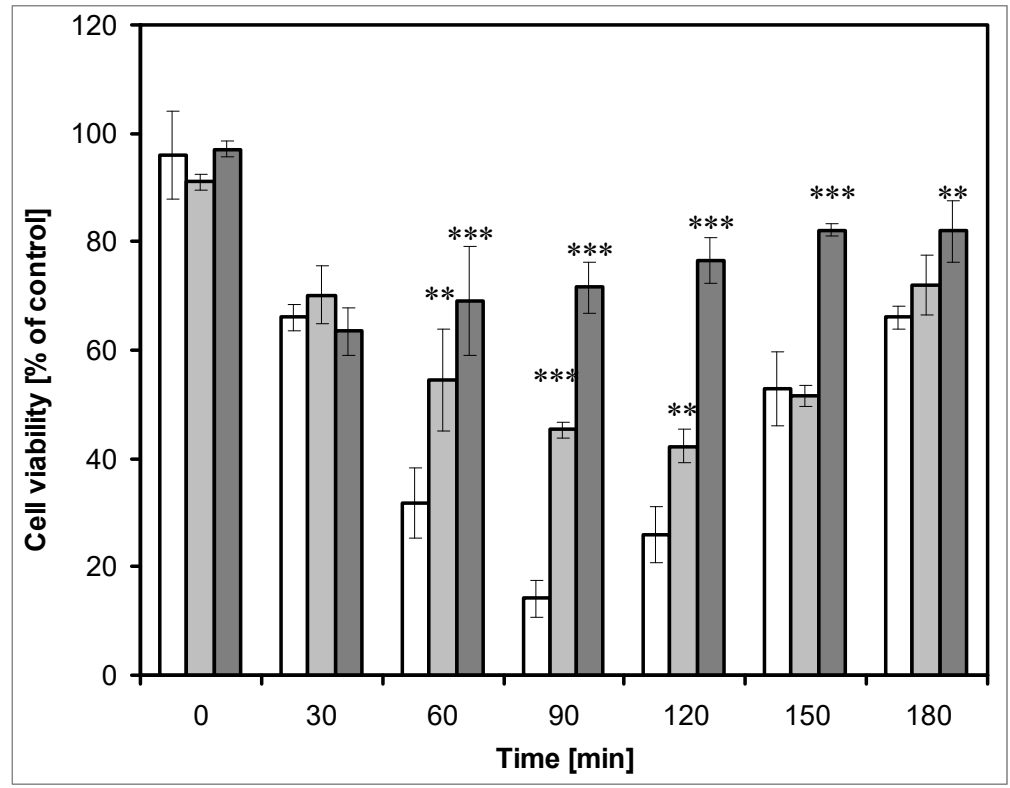

Figure 5. Changes in cell viability upon treatment with $A \beta$ 1-28 in the absence (white bars) and presence of [G3]-Mor at $0.2 \mu \mathrm{M}$ (dark grey bars) and $0.02 \mu \mathrm{M}$ (light grey bars). Molar ratios $A \beta /[G 3]-M o r$ equaled to 50 and 500 , respectively, that correspond to dendrimer concentrations of 1 and $0.1 \mu \mathrm{M}$ in the ThT assay. To check whether the presence of dendrimers affects the toxicity of $A \beta$ 1-28 species (at different stages of aggregation), the statistical significance was compared between systems with [G3]-Mor and the control (** $\left.p<0.01,{ }^{* * *} p<0.005\right)$. 


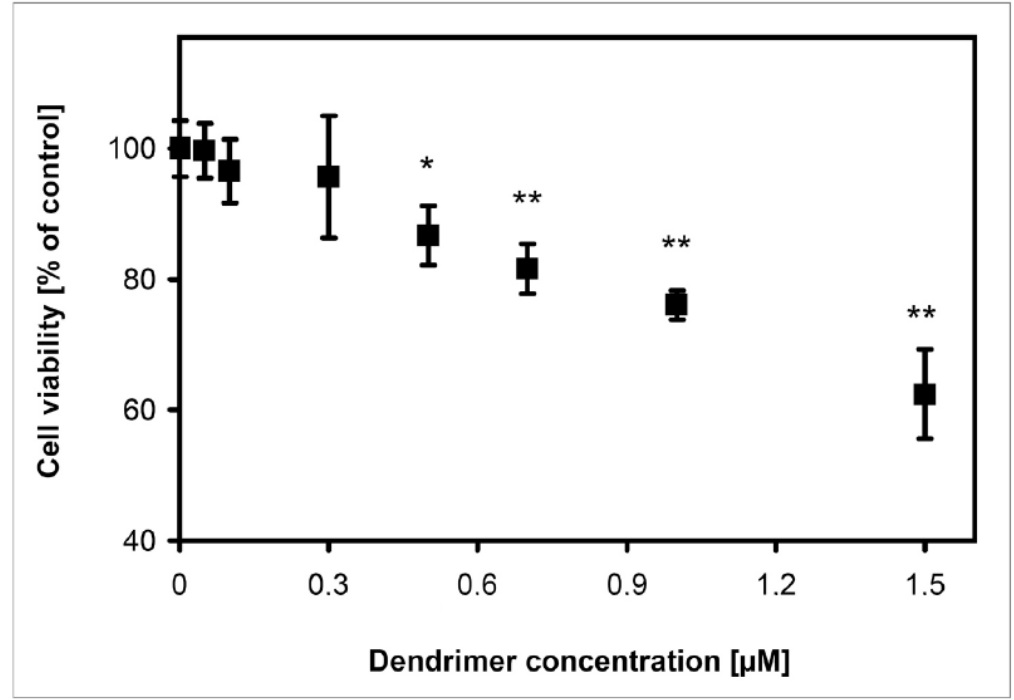

Figure 6. Changes in cell viability after treatment with [G3]-Mor at different concentrations (* $\left.p<0.05,{ }^{* *} p<0.01\right)$. 